\title{
Characteristics Analysis of Badminton in Female Single Player
}

\author{
Nugroho Agung Supriyanto \\ Departement of Physical Education \\ STKIP PGRI Sumenep \\ Sumenep, Indonesia \\ agungnugroho@stkippgrisumenep.ac.id
}

\author{
Ainur Rasyid \\ Departement of Physical Education \\ STKIP PGRI Sumenep \\ Sumenep, Indonesia \\ ainurrasyid@stkippgrisumenep.ac.id
}

\begin{abstract}
-badminton is characterized by the types of stroke used to win a match. This study aim is to describe the various strokes capable of producing some points in a female single game of badminton. Five female badminton players were used to carry out this research study in a match carried out using a single rally point system. A descriptive method was used to record and analyzed the various types of stroke producing points used. The results obtained showed that unforced errors made by the opponent team, lead to production of some amazing points. The same was with the losing team. The common types of unforced errors frequently made by them was that they were in the habit of catching strokes inside the net. Similarly, the types of unforced errors frequently made by a winning team were stroke out and stroke caught in the net. Players who committed a few unforced errors during the match had a great chance to win the match.
\end{abstract}

Keywords-Badminton, female single, stroke, unforced errors

\section{INTRODUCTION}

Badminton is a popular sport in Asia. The game was first played at the 1992 Barcelona Olympics [4, 7]. Badminton is an explosive sport owing to the fact that it relies on fast movements with a confined area [9]. Badminton can be played by male single and female single, double, and mixed form.

The characteristics of badminton is dependent on the types of stroke used for attack or defense. The types of stroke in badminton are lop, backhand, netting, clear, drop-shot, drive, and smash $[1,6]$. These different stroke types, greatly affect the outcome of a badminton match in accordance with the strategies and techniques used. Each stroke gives different response to the opponent, thereby, creating an advantageous medium for more points to be achieved.

Over the years, the game of badminton has undergone some series of changes [5]. The new regulations created some minor changes to the strategy, tactics, and training program initiated in learning the game and implemented during the match. According to M. Chin, et al. (1995), to succeed in any game of sports, the players employ some psychological strategies, techniques, and tactics during a match.. The current rule added to the game of badminton is the rally point system [2]. This rule has it that a player must collect a total of 21 points within 2 sets in one match. This rule marks all the in or out strokes as well as the unforced errors committed by the player as a point, thereby, making players play more carefully.
The aim of this study is to describe the characteristics of a badminton match based on the types of strokes that produces some points a single female match.

\section{METHOD}

\section{A. Subject}

The research subjects used in carrying out this study are five Sumenep Regency female badminton players. The anthropometric and characteristics of the subjects is tabulated in table I below. From the table, it can be seen that the athlete has already participated in several junior-level matches.

\section{B. Procedure}

First, the subject is briefed on the aim, objectives, and benefits of the game, after which, a draw is taken to determine who starts the game. Before the commencement of the match, each player is given amble time to warm up and adapt to the court in order to reduce the risk of injury during the match. The match is carried out in a single form. A total number of 5 matches are contested. A rally points system was used to determine the winning team in each match. The wining team is any team capable of gaining a total of 21 points within 2 sets in one match. The rules and counting points technique used was the regulation set by BWF.

\section{RESULT}

The matches recorded and analyzed were 5 matches which was finished in 2 sets. The points produced in the badminton match came from several strokes and unforced errors made by the opponent. The result of the points obtained from the games of badminton, can be seen in table II.

The highest point generated by the winning team in one match was as a result of unforced errors caused by the opponent's stroke which were $13.2 \pm 4.32$ points with a percentage of $31.43 \%$. Similarly, the losing team points were caused by the opponent's unforced error strokes which were $11 \pm 4.06$ points with a percentage of $39.01 \%$.

The various types of unforced errors obtained by winning and losing players are shown in table II. The types of unforced errors carried out by the winning players was stroke out which produced $5.2 \pm 2.38$ points with a percentage of $47.27 \%$, while the stroke caught in the net produced $5.2 \pm$ 2.38 points with a percentage of $47.27 \%$. The type of unforced errors often conceived by the losing team was stroke caught in the net which produced $5.8 \pm 2.77$ points with a 
percentage of $43.94 \%$. The points produced by the opposing unforced errors had an advantage over the opposing team.

The type of stroke that mostly produce points from a team player's stroke was smash. The winning team had a smash stroke of $10.2 \pm 3.96$ points with a percentage of $24.29 \%$, while the losing team had a smash stroke of $5.6 \pm 2.30$ points with a percentage of $19.85 \%$.

TABLE I. ANTHROPOMETRIC AND CHARACTERISTICS OF THE SUBJECTS

\begin{tabular}{|l|c|}
\hline Anthropometric and Characteristics & Average \\
\hline Age (year) & $15,8 \pm 0,83$ \\
\hline Weight $(\mathrm{kg})$ & $50,8 \pm 1.09$ \\
\hline Height $(\mathrm{m})$ & $1.55 \pm 0.05$ \\
\hline
\end{tabular}

TABLE II. Types Of Strokes ANd Unforced Errors Producing Points In EACH Match

\begin{tabular}{|l|c|c|c|c|}
\hline \multirow{2}{*}{ Types of Stroke } & \multicolumn{2}{|c|}{ Winning Player } & \multicolumn{2}{c|}{ Losing Player } \\
\cline { 2 - 4 } & $\begin{array}{c}\text { Point } \\
\text { (Point) }\end{array}$ & $\begin{array}{c}\text { Percentage } \\
\text { (\%) }\end{array}$ & $\begin{array}{c}\text { Point } \\
\text { (Point) }\end{array}$ & $\begin{array}{c}\text { Percentage } \\
\text { (\%) }\end{array}$ \\
\hline Lob & $2 \pm 1.22$ & 4.76 & $2 \pm 1.41$ & 7.09 \\
\hline Drop-shot & $3 \pm 2.54$ & 7.14 & $2.4 \pm 0.54$ & 8.51 \\
\hline Smash & $10.2 \pm 3.96$ & 24.29 & $5.6 \pm 2.30$ & 19.85 \\
\hline Drive & $1.8 \pm 1.48$ & 4.29 & $1.4 \pm 1.51$ & 4.96 \\
\hline Backhand & $3.6 \pm 3.04$ & 8.57 & $1.2 \pm 0.44$ & 4.26 \\
\hline Netting & $4.2 \pm 0.83$ & 10 & $3.4 \pm 0.54$ & 12.06 \\
\hline Serve & $2.6 \pm 3.78$ & 6.19 & $0.6 \pm 0.54$ & 2.13 \\
\hline Forehand & $1.4 \pm 0.54$ & 3.33 & $0.6 \pm 0.89$ & 2.13 \\
\hline Opponent's Unforced errors: & $13.2 \pm 4.32$ & 31.43 & $11 \pm 4.06$ & 39.01 \\
a. Serve failure & $1.8 \pm 3.03$ & 13.64 & $0.6 \pm 0.54$ & 5.46 \\
b. Stroke out & $5.6 \pm 2.41$ & 42.42 & $5.2 \pm 2.38$ & 47.27 \\
c. Stroke get caught in the net & $5.8 \pm 2.77$ & 43.94 & $5.2 \pm 2.38$ & 47.27 \\
\hline
\end{tabular}

\section{DISCUSSION}

Badminton is a sport that requires a variety of stroking techniques and strategies to win the match. Badminton players require good stroke techniques, excellent physical structure and good body physic to reach the maximum performance [9]. Players must be trained in accordance to these three skills in order to achieve maximum performance. Winners are usually players who commit few unforced errors $[1,4]$. The number of unforced errors committed by a team will make the opponent team stand a better chance of winning the match. It is, therefore, important for team players to be mentally and physically stable to ensure they minimize the type of unforced errors $h$.

The unforced errors can be prevented from the beginning of a match. The results obtained shows that the players still committed unforced errors even while serving. Serve is the act of taking the first stroke with the commencement of the match. Errors associated with serve can be reduced by consistent practice. Any player that wishes to partake in the serve, must mentally and physically fit [4]. The stroke out and the stroke get caught in the net are caused by to the urge to quickly complete the match rally. This ideology would be to the detriment of the match. This causes loss of concentration and increased unforced errors. The game of badminton is related to long and short rallies [8]. The winner of the rally should be able to determine the types of stroke that will be used in accordance with the situation and condition in the court.

The stroke that produces the most points is the smash. Badminton players use smash stroke a lot to produce points and end a rally. Smash stroke is most times used for attack. It has a higher speed compared to other strokes with its speed reaching about $68 \mathrm{~m} / \mathrm{s}$ [3] making it pretty difficult for an opponent to block or return a smash stroke. The effect of a smash, depends on the wrist, shoulder, and elbow, therefore, coaches should ensure they give special exercises to their players in order to improve the speed and accuracy of the smash strokes.

Badminton does not only depend on smashes to produce points, it also depends on some other types of strokes used to produce points in rally. The types of stroke are chosen according to the strategy, tactics, and types of opponents encountered. The players must be able to combine the different types of strokes in order to be able to produce as many points. They should also try as much as possible to reduce unforced errors as the match progresses.

\section{CONCLUSION}

This research study can be concluded by saying that the winning team in the game of badminton match was the team who committed fewer unforced errors. The player who committed fewer unforced errors had greater chance of winning the match. The stroke which produced most points was unforced error committed by the opponent. Coaches should ensure that the carry out adequatetraining programs on their players in order to minimize unforced errors and stroke caught in the net. Further research on this topic, should make use of a larger number of matches and more physiological measurement of each badminton player should be taken into consideration during the match. 


\section{REFERENCES}

[1] A. Milon, and B. Milon. "A comparative study on the unforced errors and decisive points in junior badminton matches". Gymnasium Journal of Physical Education and Sport. No. 1, Vol XI, 2010.

[2] Badminton World Federation. BWF Handbook II (Laws of Badminton \& Regulations). Stadium Badminton Kuala Lumpur Malaysia: BWF. 2010. Available from: www.worldbadminton.com/rules/documents/bwfHandbook2010.pdf

[3] C. L. Tsai, C. Huang, D. C. Lin and S. S. Cheng. Biomechanical analysis of the upper extremity in three different badminton overhead strokes. In Proceedings of XVIII International Symposium on Biomechanics in Sports. Hong Kong, The Chinese University of Hong Kong. 2000.

[4] D. Cabello Manrique and J. J. Gonzalez-Badillo. "Analysis of the characteristics of competitive badminton". $\mathrm{Br} \mathrm{J}$ Sports Med. 2003;37:62-66.
[5] D.F. Percy. "A mathematical analysis of badminton scoring systems". Journal of the Operational Research Society. 2009; 60:63-71.

[6] J. Wang and L. Wenhao. "Changes in badminton game play across developmental skill levels among high school students". Journal of Research. Volume 7, issue 1, pp. 29-37, 2012.

[7] M. Chint, et al. "Sport specific fitness testing of elite badminton players". Br. J. Sports Med. Vol. 29, No. 3, pp. 153-157, 1995.

[8] O. Faude, et al. "Physiological characteristics of badminton match play". Eur J Appl Physiol. 2007;100:479-485.

[9] R. Jeyaraman, and Dr. R. Kalidasan. "Prediction of playing ability in badminton from selected anthropometrical physical and physiological characteristics among inter collegiate players". IJAIR. pp. 47-58, 2012. 